\title{
Abatacept: the evidence for its place in the treatment of rheumatoid arthritis
}

\author{
Marcus D. Köller \\ Medical University of Vienna, Vienna, Austria
}

\begin{abstract}
Introduction: Rheumatoid arthritis $(\mathrm{RA})$ is the most common inflammatory joint disease in adults with a prevalence of $0.5-1 \%$. The development of targeted therapies, especially anti-TNF (tumor necrosis factor) treatment, has improved disease outcome during the last decade. But despite this progress $25-30 \%$ of patients still show unsatisfactory response. Abatacept is a costimulation blocker that inhibits T-cell activation and interrupts the process that leads to inflammation in RA.
\end{abstract}

Aims: The purpose of this article is to review the clinical trials of abatacept and to discuss how it will fit into the treatment of RA. The medical literature was reviewed for appropriate articles and 123 articles have been identified containing the search terms "abatacept OR CTLA4-Ig AND rheumatoid." All clinical trials were reviewed with respect to clinical and radiologic outcome, quality of life, and safety of patients with RA receiving abatacept therapy.

Evidence review: There are seven (phase II or phase III) clinical trials that have clearly demonstrated efficacy and safety of this new drug. Furthermore, radiographic data show that abatacept also inhibits the progression of joint destruction, one of the important burdens of RA. Abatacept can be used concomitantly with conventional disease-modifying antirheumatic drugs or as monotherapy. Due to an increased risk of infections and malignancies but without an important enhancement of efficacy, simultaneous treatment with abatacept and other biologic response modifiers is not recommended.

Place in therapy: With its different mechanism of action, abatacept may be an alternative therapy for patients with an inadequate response to other arthritis therapies, especially for those patients with RA refractory to anti-TNF treatment. Cost effectiveness is dependent on underlying disease progression.

Core Evidence. 2007;2(3):163-172.

Key words: abatacept, biologics, disease-modifying antirheumatic drugs, rheumatoid arthritis

Core evidence place in therapy summary for abatacept in rheumatoid arthritis

\begin{tabular}{|c|c|c|}
\hline Outcome measure & Evidence & Implications \\
\hline Reduction of pain & Clear & Significant improvement of pain on Visual Analog Scale \\
\hline Increase of QOL & Clear & Improvement of physical and mental health \\
\hline \multicolumn{3}{|l|}{ Disease-oriented evidence } \\
\hline Reduction of synovitis & Clear & Improvement of swollen and tender joint count \\
\hline Reduction of inflammatory response & Clear & Decrease of C-reactive protein levels and biomarkers \\
\hline \multicolumn{3}{|l|}{ Economic evidence } \\
\hline Cost effectiveness & Limited & $\begin{array}{l}\text { Costs per patient and per year comparable to other biologics. Cost } \\
\text { effectiveness driven by assumptions made for disease progression }\end{array}$ \\
\hline
\end{tabular}




\section{Scope, aims, and objectives}

Abatacept (Orencia ${ }^{\circledR}$, Bristol-Myers Squibb) is a drug used in targeted therapy of rheumatoid arthritis (RA). It exerts an antiinflammatory action by the inhibition of T-cell activation. Its use is recommended for treatment-resistant patients with RA after ineffective therapy with one or more disease-modifying antirheumatic drugs (DMARDs). After an initial loading period of three intravenous infusions every other week, abatacept is given every 4 weeks. Several clinical trials have demonstrated the efficacy of this new drug. Furthermore, radiographic data show that abatacept also slows the progression of joint destruction, one of the important burdens of RA. The purpose of this article is to review the clinical trials of abatacept and to discuss how it will fit into the treatment of RA.

\section{Methods}

The medical literature was reviewed for appropriate articles relating to abatacept on PubMed (http://www.ncbi.nlm.nih.gov) using the search terms "abatacept OR CTLA4-Ig AND rheumatoid." The search was updated on June 18, 2007. One hundred and twenty-three articles were found, of which 12 were written in languages other than English and were excluded. Within those 111 publications, 12 reports from clinical trials and 45 review articles have been identified. Out of the reports from clinical trials, 11 are included and also cited in this review (Table 1). The excluded clinical trial article was

Table 1 | Evidence base included in the review

\begin{tabular}{|lcc|}
\hline Category & Number of records \\
\cline { 2 - 3 } & Full papers & Abstracts \\
\hline Initial search & 123 & 34 \\
records excluded & 66 & 24 \\
records included & 57 & 10 \\
Additional studies identified & 0 & 1 \\
Total records included & 11 & 11 \\
Level 1 clinical evidence & 0 & 1 \\
(systematic review, meta analysis) & & 6 \\
Level 2 clinical evidence (RCT) & 7 & 3 \\
Level $\geq 3$ clinical evidence & 0 & 1 \\
$\quad$ trials other than RCT & & \\
$\quad$ case reports & 0 & \\
Economic evidence & & \\
\hline For definitions of levels of evidence, see Editorial Information on inside back cover or on \\
Core Evidence website. \\
RCT, randomized controlled trial.
\end{tabular}

out of scope as its aim was to compare health assessment scales. In addition, one abstract has been published presenting clinical data, which is included in the Place in therapy section. Thirty-four further abstracts were identified from the European League Against Rheumatism (EULAR) 2007 congress (http://www.abstracts2view.com/eular), of which 10 were considered relevant.
The results of the included clinical trials are reviewed, focusing on clinical and radiologic efficacy, quality of life, and safety of abatacept in patients with RA. There are seven phase II and III clinical trials, and a further four reports show data not of primary endpoints derived from these trials. No pharmacoeconomic studies of abatacept in RA were identified.

\section{Disease overview}

$\mathrm{RA}$ is the most common inflammatory joint disease in adults with a prevalence of $0.5-1 \%$. The disease has a worldwide distribution and affects all ethnic groups at any age; its prevalence increases with age with an incidence maximum between the fourth and sixth decade. Both genders are affected but two-thirds of patients are female (Gabriel 2001).

Epidemiologic studies and clinical trials are based on the classification criteria of the American College of Rheumatology (ACR) for RA (Arnett et al. 1988). Signs and symptoms, namely joint swelling and pain, are caused by an inflammation of the synovial membrane. This multifactorial autoimmune process is triggered by unknown causes and mediated by a complex cascade of cellular and humoral (inter)actions. The migration of leukocytes into the joints and the activation of osteoclasts results in synovitis and bone erosions (Redlich et al. 2002). There is increasing evidence that this damage and its functional consequences occur early in the course of the disease. Several studies show that $39-73 \%$ of patients develop erosions in their hands and wrists within 5 years. After 20 years RA patients have on average $43 \%$ of maximum possible damage and only $25 \%$ are still nonerosive at this time (Scott 2004). A common goal is early and aggressive therapy to achieve better prognosis of this chronic disease (Quinn et al. 2001; Quinn \& Emery 2005; Smolen et al. 2005a). Extraarticular manifestations can include rheumatoid nodules, vasculitis, episcleritis, pulmonary fibrosis, lymphadenopathy, or fever. Furthermore, the chronic inflammatory response is associated with an elevated risk of osteoporosis, cardiovascular events, infections, secondary amyloidosis, or lymphoproliferative malignancies. Several studies demonstrate an increased mortality in patients with RA, with a standardized ratio between 1.28 and 2.98. The disease reduces life expectancy by 7 years for men and 3 years for women (Mikuls \& Saag 2001).

\section{Current therapy options}

Although the causes of RA are still not completely elucidated, several pathways and mechanisms in the perpetuation of inflammation have been well characterized. Over the last two decades, advances in the knowledge of molecular biologic techniques have led to a better understanding of immunopathogenesis, which propagates chronic arthritis (Smolen et al. 2004, 2005b). The complex network of cellular and humoral interactions opens up a broad spectrum of potential therapeutic targets. Continued research toward new and better-tolerated therapies to attenuate the inflammation and pain associated with RA and to halt the progression of erosive joint damage has led to the development of strategies blocking cytokines or modulating 
the costimulation of immune cells. Such agents are called "biologics," an abbreviated colloquial term for "biologic response modifiers" (Köller 2006).

Beside nonsteroidal antiinflammatory drugs (NSAIDs) and corticosteroids, DMARDs such as methotrexate, sulfasalazine, leflunomide, cyclosporin A, azathioprine, and (hydroxy-) chloroquine are essential and therefore used to reduce synovitis. A number of biologic agents have been developed to target different immune markers or mediators with the hope that they may help to control the inflammation in patients who are resistant to treatment with conventional DMARDs. Especially in adult RA, several biologic agents targeting different mediators, like tumor necrosis factor (TNF)-alfa, interleukin (IL)-1, and IL-6, have been investigated in clinical trials (Table 2). Also targeting B lymphocytes decreases disease avtivity of RA (Edwards et al. 2004; Köller 2006).

Table 2 | Biologic disease-modifying antirheumatic drugs currently available or in phase III trials

\begin{tabular}{|c|c|c|c|}
\hline Mechanism & $\begin{array}{l}\text { Target } \\
\text { molecule(s) }\end{array}$ & $\begin{array}{l}\text { Therapeutic } \\
\text { agent }\end{array}$ & $\begin{array}{l}\text { Molecule } \\
\text { structure }\end{array}$ \\
\hline \multirow[t]{3}{*}{ TNF blockade } & $\operatorname{mTNF} \alpha+\operatorname{sTNF} \alpha$ & Infliximab & Chimeric mab \\
\hline & $\operatorname{sTNF} \alpha$ & Etanercept & TNFR2-Ig \\
\hline & $\operatorname{mTNF} \alpha+\operatorname{sTNF} \alpha$ & Adalimumab & Human mab \\
\hline $\begin{array}{l}\text { IL-1 receptor } \\
\text { blockade }\end{array}$ & IL-1R & Anakinra & Human IL-1RA \\
\hline B-cell depletion & CD20 & Rituximab & Chimeric mab \\
\hline $\begin{array}{l}\text { Costimulation } \\
\text { blockade }\end{array}$ & CD80/CD86 & Abatacept & CTLA4-lg \\
\hline $\begin{array}{l}\text { IL-6 receptor } \\
\text { blockade }\end{array}$ & IL-6R & Tocilizumab & Human mab \\
\hline \multicolumn{4}{|c|}{$\begin{array}{l}\text { CTLA4, cytotoxic T-lymphocyte-associated protein 4; Ig, immunoglobulin; IL-1(RA), } \\
\text { interleukin-1(receptor antagonist); IL-6(R), interleukin-6(receptor); mab, monoclonal } \\
\text { antibody; }(\mathrm{m} / \mathrm{s}) \mathrm{TNF}(\mathrm{R}) \text {, (membrane/soluble) tumor necrosis factor (receptor). }\end{array}$} \\
\hline
\end{tabular}

The approach to the treatment of RA has changed in the last 10 to 15 years. In most cases conventional DMARDs are the first-choice therapy of established RA. Methotrexate, if not contraindicated, remains the gold standard in this armamentarium. Other drugs, namely sulfasalazine or leflunomide, have been demonstrated to be of equal potency. However, TNF-alfa-blocking agents have particularly improved outcomes in RA treatment and therefore their use has been investigated in early stages of disease. It has been shown that anti-TNF therapy, particularly in combination with methotrexate at the beginning of treatment, is superior in improving clinical outcome and preventing radiologic damage compared with methotrexate treatment alone in patients with highly active disease (Genovese et al. 2002; Breedveld et al. 2006). However, in general up to $25 \%$ of patients fail to respond adequately to TNF blockade or develop loss of efficacy, therefore new therapy options are still required (Keystone \& Kavanaugh 2005).

Evidence from different experimental approaches suggest that T cells play an important role in the pathogenesis of RA (Goronzy
\& Weyand 2004; Skapenko et al. 2005). Another therapeutic option is to block cellular interactions, namely costimulatory signals which are essential for the stimulation of T lymphocytes. One of these signals is induced by the interaction of CD80/86 on antigen-presenting cells (APCs) and CD28 on T cells. Cytotoxic T-lymphocyte-associated protein 4 (CTLA4) is a protein homologous to CD28, which is expressed mainly by activated T cells. It competes with CD28 for binding to CD80/CD86 with a much higher affinity for these ligands, and provides a negative feedback loop (Sfikakis \& Via 1997).

Abatacept is a soluble fusion protein consisting of the extracellular domain of human CTLA4 and an Fc-fragment of an immunoglobulin (Ig), namely IgG1. By binding to CD80 and CD86 ligands on the APCs it prevents a costimulatory signal by CD28 (Dumont 2004). The ability of CTLA4-Ig to block T-celldependent primary and secondary immune responses has been demonstrated in murine and primate models (Webb et al. 1996; Quattrocchi et al. 2000).

\section{Clinical evidence for abatacept in rheumatoid arthritis}

Experimental data from animal models have demonstrated that the administration of CTLA4-Ig ameliorates collagen-induced arthritis in mice (Knoerzer et al. 1995). Thereafter, several clinical trials have shown biologic effects and proven the efficacy of abatacept in the treatment of RA in humans.

The pharmacokinetic parameters of abatacept were studied in healthy volunteers who received a single $10 \mathrm{mg} / \mathrm{kg}$ dose or patients with RA who received multiple doses. The pharmacokinetic parameters in these two populations were comparable, with a mean a half-life of 13.1 days (range 8-25 days). No accumulation was seen after monthly repeated infusions. A slightly increased clearance was observed with increasing bodyweight, but no age or sex differences were noted, which finally led to the recommendations of dose adjustment to bodyweight (Moreland et al. 2002).

At the doses of $2 \mathrm{mg} / \mathrm{kg}$ or $10 \mathrm{mg} / \mathrm{kg}$ used in further clinical studies, abatacept decreased serum levels of proinflammatory cytokines and inflammatory responses, including soluble IL-2 receptor, IL-6, E-selectin, TNF-alfa, rheumatoid factor, and C-reactive protein levels (Weisman et al. 2006). Although abatacept inhibits T-cell function it does not deplete $\mathrm{T}$ cells (Kremer 2004).

\section{Clinical efficacy assessment}

Clinical efficacy and current disease activity can be measured in several ways using different scores. Response criteria according to the ACR allow judging improvement or change from baseline but not the actual state of disease activity. An ACR20, 50, or 70 response is defined as a $20 \%, 50 \%$, or $70 \%$ reduction in the number of swollen and tender joints, as well as some other core sets of laboratory parameters or quality-of-life settings (Table 3). 
Table 3 | American College of Rheumatology disease-response criteria (Felson et al. 1995)

Swollen joint count (66 joints)

Tender joint count (68 joints)

Subject global assessment of pain (VAS $100 \mathrm{~mm}$ )

Subject global assessment of disease activity (VAS $100 \mathrm{~mm}$ )

Physician global assessment of disease activity (VAS $100 \mathrm{~mm}$ )

Subject assessment of physical function using $\mathrm{HAQ}$

C-reactive protein

The ACR20 $(50,70)$ definition of response specifies a $20 \%(50 \%, 70 \%)$ improvement over

baseline in swollen and tender joints and in $3 / 5$ of the remaining core data set measures.

HAQ, Health Assessment Questionnaire; VAS, Visual Analog Scale.

Additional outcome measures commonly used mainly in clinical practice include the Disease Activity Score (DAS)-28, which is calculated using tender and swollen joint count out of 28 joints investigated, erythrocyte sedimentation rate, as well as estimation of disease activity by the patient on a $100 \mathrm{~mm}$ Visual Analog Scale (VAS), which provides a continuous measure of disease activity. A DAS-28 score of $<2.6$ indicates remission, $\leq 3.2$ indicates low disease activity, while scores of $\geq 5.1$ define high disease activity (Prevoo et al. 1995).

Patients with RA not only suffer from pain, stiffness, swelling, and joint destruction, but also with loss of physical function. Therefore, assessment of disability and health status reflecting patients' quality of life is also a pivotal aspect in any therapeutic trial. The instrument most frequently used for evaluating functional impairment is the Health Assessment Questionnaire Disability Index (HAQ-DI), while health status is most often evaluated by the Medical Outcomes Study Short Form (SF)-36 (Doyle 2001).

Prevention of joint destruction which may not be reversible is one of the key desired effects of treatment with new antiinflammatory drugs. Joint space narrowing and bone erosions evaluated on plain joint radiographs reflect the grade of joint damage. The most often-used assessment tools for evaluating joint destruction is the Sharp score and its modifications (Pincus et al. 1997; Lassere 2000).

\section{Clinical efficacy in phase II and III trials}

Abatacept was approved by the Food and Drug Administration (FDA) on December 23, 2005 for reducing the signs and symptoms of moderate to severe RA in adult patients who have had an inadequate response to at least one DMARD (FDA 2005). The main basis for this decision included phase II and phase III randomized, double-blind, placebo-controlled trials in adult RA patients showing data over a treatment period of 6 or 12 months.

In a phase Ilb, multicenter, international study two dosages of abatacept $(2 \mathrm{mg} / \mathrm{kg}$ and $10 \mathrm{mg} / \mathrm{kg}$ ) were compared in patients with RA who had active disease despite methotrexate therapy. Abatacept was given intravenously over 30 min on day 1, 15, 30, and every 4 weeks thereafter for 6 months. In total 339 patients were treated, of whom 119 were assigned to placebo, another
105 received the low dosage, and 115 were treated with the higher dose, all of them while continuing methotrexate. Sixty percent of the patients in the $10 \mathrm{mg} / \mathrm{kg}$ group achieved an ACR20 response, compared with $41.9 \%$ in the lower dose group and in $35.3 \%$ of the placebo-treated patients (Kremer et al. 2003). Evaluation of ACR50 and ACR70 responses also favored the higher dosage, although both dosages of abatacept were significantly better than placebo (Table 4). There was no significant difference in ACR20 response rates between the $2 \mathrm{mg} / \mathrm{kg}$ dosage group and placebo patients.

Table 4 | Response to abatacept or placebo after 6 months in patients with active rheumatoid arthritis despite methotrexate treatment (percentage of patients) (Kremer et al. 2003)

\begin{tabular}{|c|c|c|c|}
\hline & $\begin{array}{l}\text { Abatacept } \\
2 \mathrm{mg} / \mathrm{kg}(\%)\end{array}$ & $\begin{array}{l}\text { Abatacept } \\
10 \mathrm{mg} / \mathrm{kg}(\%)\end{array}$ & $\begin{array}{l}\text { Placebo } \\
(\%)\end{array}$ \\
\hline ACR20 response & $41.9(P=0.31 ; \mathrm{NS})$ & $60.0(P<0.001)$ & 35.3 \\
\hline ACR50 response & $22.9(P<0.05)$ & $36.5(P<0.001)$ & 11.8 \\
\hline ACR70 response & $10.5(P<0.05)$ & $16.5(P<0.001)$ & 1.7 \\
\hline \multicolumn{4}{|c|}{$\begin{array}{l}\text { The ACR20 }(50,70) \text { definition of response specifies a } 20 \%(50 \%, 70 \%) \text { improvement over } \\
\text { baseline in swollen and tender joints and in } 3 / 5 \text { of the remaining core data set measures. } \\
\text { NS, not significant. }\end{array}$} \\
\hline
\end{tabular}

An extension of this study revealed similar results after 12 months of treatment (Kremer et al. 2005). At day 360, 62.6\% in the $10 \mathrm{mg} / \mathrm{kg}$ group showed an ACR20 response versus $36.1 \%$ in the placebo group $(P<0.001)$. No significant differences were found between abatacept $2 \mathrm{mg} / \mathrm{kg}$ and placebo, whereas improvement in ACR50 and ACR70 was significantly greater with abatacept $10 \mathrm{mg} / \mathrm{kg}$ (Table 5). The higher dose of abatacept also showed significantly higher improvement in quality-of-life parameters, whereas the $2 \mathrm{mg} / \mathrm{kg}$ group showed a very weak and transient response (Emery et al. 2006). These results confirm that abatacept $2 \mathrm{mg} / \mathrm{kg}$ is suboptimal for effective treatment of active RA.

\begin{tabular}{|c|c|c|c|}
\hline & $\begin{array}{l}\text { Abatacept } \\
10 \mathrm{mg} / \mathrm{kg}(\%)\end{array}$ & Placebo (\%) & $P$ value \\
\hline ACR20 response & 62.6 & 36.1 & $<0.001$ \\
\hline ACR50 response & 41.7 & 20.2 & $<0.001$ \\
\hline ACR70 response & 20.9 & 7.6 & $<0.001$ \\
\hline
\end{tabular}

The ACR20 $(50,70)$ definition of response specifies a $20 \%(50 \%, 70 \%)$ improvement over baseline in swollen and tender joints and in $3 / 5$ of the remaining core data set measures.

The Abatacept Trial in the Treatment of Anti-TNF Inadequate Responders (ATTAIN) investigated the efficacy of abatacept in patients with RA who failed anti-TNF therapy either with etanercept or infliximab (Genovese et al. 2005). Patients had to be on anti-TNF-alfa treatment for at least 3 months before entering the study. Two groups were enrolled: "current users" who were on 
anti-TNF treatment at the time of screening, and "former users" who had previously received such therapy. Wash-out periods were $\geq 28$ days for etanercept and $\geq 60$ days for infliximab. All patients stayed on concomitant immunosuppressive therapy with an oral conventional DMARD (mostly methotrexate) or anakinra (Table 6).

\section{Table 6 | Concomitant DMARD therapy in the ATTAIN trial} (Abatacept Trial in the Treatment of Anti-TNF Inadequate Responders) (Genovese et al. 2005)

\begin{tabular}{|lcc|}
\hline DMARD & Abatacept (\%) (n=256) & Placebo (\%) (n=133) \\
\hline Methotrexate & 75.6 & 82.0 \\
Leflunomide & 8.9 & 8.3 \\
Sulfasalazine & 7.0 & 9.8 \\
Azathioprine & 2.7 & 2.3 \\
Hydroxychloroquine & 8.9 & 9.0 \\
Chloroquine & 0.0 & 0.8 \\
D-penicillamine & 0.4 & 0.0 \\
Gold salts & 0.0 & 0.8 \\
Anakinra & 2.7 & 2.3 \\
\hline DMARD, disease-modifying antirheumatic drug. & \\
\hline
\end{tabular}

Two hundred and fifty-six patients were randomly assigned to abatacept (approximately $10 \mathrm{mg} / \mathrm{kg}$ ) in a double-blind fashion. Patients with bodyweight $<60 \mathrm{~kg}$ received $500 \mathrm{mg}$, those weighing 60 to $100 \mathrm{~kg}$ received $750 \mathrm{mg}$, and patients weighing $>100 \mathrm{~kg}$ were treated with $1000 \mathrm{mg}$ of abatacept, which are also the doses now recommended for clinical use. The initial dose was followed by repeat doses 2 and 4 weeks later and every 4 weeks thereafter (Bristol-Myers Squibb 2005). One hundred and thirty-three patients were included in the placebo arm. After 6 months, 233 of the abacept group and 99 of those on placebo finished the double-blind period, of whom 317 entered an openlabel extension with abatacept treatment following the dosage schedule described above.

Primary endpoints were percentage of patients achieving an ACR20 response and a significant improvement ( $\geq 0.3$ unit) in HAQ-DI score. Secondary endpoints included percentage of patients achieving ACR50 and ACR70 responses, remission according to DAS-28 ( $\leq 2.6)$, low disease activity (DAS-28, $\leq 3.2$ ), and changes in health-related quality of life assessed by SF-36. Additionally, the question of safety issues was addressed. Patient demographics are given in Table 7. Two-thirds of the patients were treated with infliximab and one-third with etanercept before randomization. After a protocol amendment, some patients with treatment failure of adalimumab also entered the study.

After 6 months one-half of the patients treated with abatacept achieved an ACR20 response. In contrast this was observed only in approximately $20 \%$ of the patients receiving placebo. Significant differences were also observed for ACR50 and ACR70 responses as well as low disease activity or remission according to the DAS-28 (Fig. 1). At the end of the blinded study phase after 6 months, significantly more patients achieved low disease activity or remission with abatacept than with placebo (Fig. 2).

After 18 months of abatacept treatment (1 year in the open extension phase of the study) the percentage of patients who achieved remission significantly increased up to $22.5 \%, 10 \%$ of whom had been in remission after 6 months. Furthermore, 20.6\% of the patients of the former placebo group achieved remission of disease after 1 year of abatacept treatment; only $0.8 \%$ of these

\begin{tabular}{|c|c|c|}
\hline & Abatacept $(n=256)$ & Placebo $(n=133)$ \\
\hline Age (years) & 53.4 & 52.7 \\
\hline Female (\%) & 77.1 & 79.7 \\
\hline Mean duration of RA (years) & 12.2 & 11.4 \\
\hline Rheumatoid factor-positive (\%) & 73.3 & 72.9 \\
\hline Anti-TNF current/former (\%) & $38.0 / 62.0$ & $41.4 / 58.6$ \\
\hline etanercept & 32.2 & 39.8 \\
\hline infliximab & 67.8 & 60.2 \\
\hline adalimumab & 2.3 & 1.5 \\
\hline Swollen joint count & 22.3 & 22.3 \\
\hline Tender joint count & 31.2 & 32.8 \\
\hline Pain (VAS in mm) & 70.8 & 69.9 \\
\hline DAS-28 & 6.5 & 6.5 \\
\hline C-reactive protein (mg/dL) & 4.6 & 4.0 \\
\hline
\end{tabular}

patients had been in remission at the end of the 6-month blinded placebo period. Almost $40 \%$ in both groups showed low disease activity after 18 months of treatment. Furthermore, quality of life as evaluated by HAQ-DI and SF-36 revealed a significantly greater improvement with abatacept treatment compared with placebo (Westhovens et al. 2006); the beneficial effects of abatacept on psychologic wellbeing were further confirmed in an observational evaluation of a small subset of study participants (Hassett et al. 2007). After 2 years of abatacept treatment, the percentage of patients reporting severe fatigue, pain, and sleep problems was reduced from $68 \%, 58 \%$, and $13 \%$, to $29 \%, 9 \%$, and $4 \%$, respectively (Dougados et al. 2007a), which contributes to perceptions of quality of life. These beneficial changes in patient-reported outcomes correlated with improved ability to participate in normal daily actvities (Wells et al. 2007).

The 1-year, phase III, Abatacept in Inadequate Responders to Methotrexate (AIM) trial was designed to further evaluate the safety and clinical efficacy of abatacept in combination with methotrexate, and to assess the effects of abatacept on the radiographic progression of structural damage (Kremer et al. 


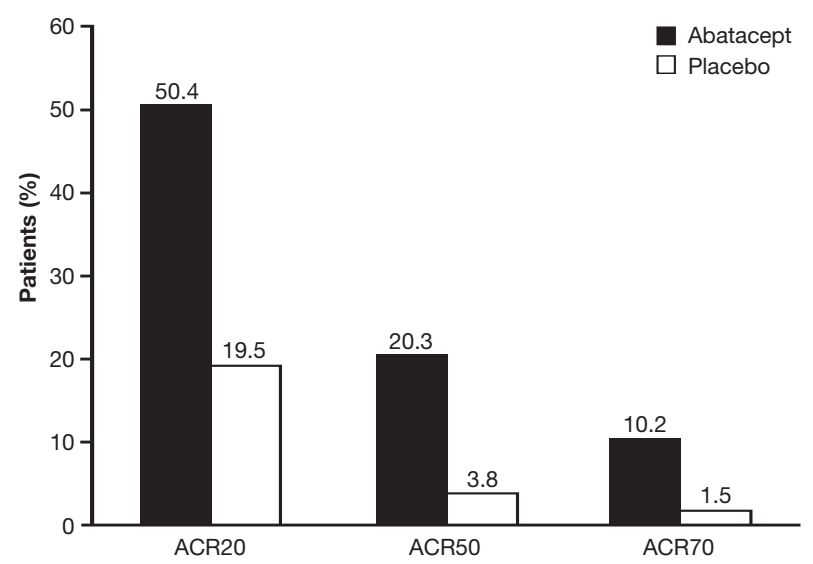

Fig. 1 | ACR response after 6 months of abatacept versus placebo following failure of anti-TNF therapy in patients with rheumatoid arthritis (ATTAIN trial) (Genovese et al. 2005). ACR, American College of Rheumatology;

TNF, tumor necrosis factor (reproduced from Genovese MC et al. N Engl J Med. 2005;353:1114-1123.

Copyright @ 2005 Massachusetts Medical Society. All rights reserved)

2006). In this multicenter, randomized, double-blind, placebocontrolled trial 656 patients with active RA despite methotrexate therapy were assigned in a ratio of $2: 1$ to additional treatment with abatacept (approximately $10 \mathrm{mg} / \mathrm{kg}$ ) or placebo. Dosage was identical to that in the ATTAIN trial. The study medication was given intravenously on days 1, 15, and 29 and then every 4 weeks up to 337 days. The dosage of methotrexate had to be $15 \mathrm{mg}$ or more per week, although methotrexate $10 \mathrm{mg}$ per week was acceptable if the patient had a history of toxicity.

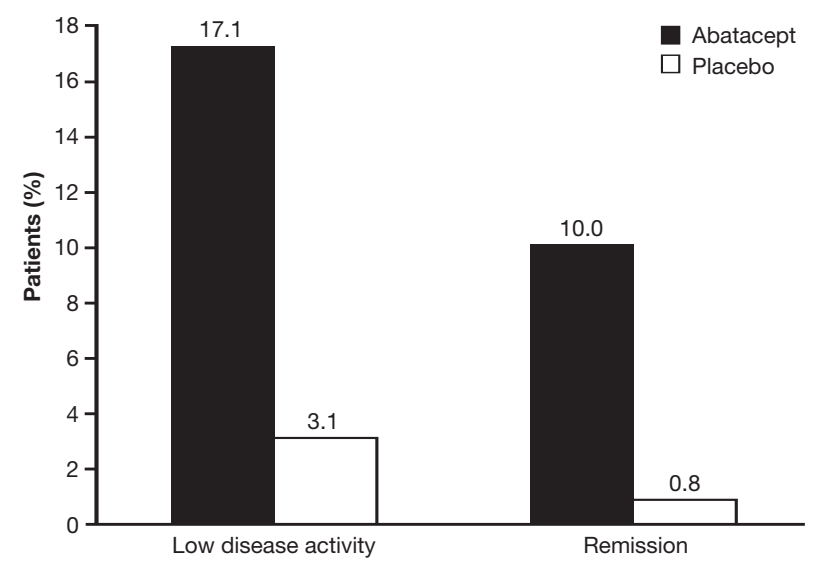

Fig. 2 | Low disease activity and remission after 6 months of abatacept or placebo treatment following anti-TNF failure in patients with rheumatoid arthritis (ATTAIN trial) (Genovese et al. 2005). TNF, tumor necrosis factor (reproduced from Genovese MC et al. N Engl J Med. 2005;353:1114-1123. Copyright @ 2005 Massachusetts Medical Society. All rights reserved)
Three hundred and eighty-five patients in the abatacept group and 162 patients receiving placebo finished 12 months of study treatment. The three primary outcome measurements were the percentage of patients with an ACR20 response after 6 months, the percentage of patients with a significant improvement $(\geq 0.3$ unit) in the HAQ-DI at 1 year, and the radiographic progression of joint erosions (assessed by comparing changes from baseline in the Genant-modified Sharp score) at 1 year. Secondary objectives included ACR50 and ACR70 responses at 6 months and all ACR responses at 1 year. In addition, the proportions of patients achieving a major clinical response at 1 year were analyzed. Furthermore, changes in disease activity by using the DAS-28 and changes in health-related quality of life using the SF-36 were evaluated.

More patients in the abatacept group (89\%) than in the placebo group $(74 \%)$ completed 1 year of treatment. There were no differences in the mean dosage of methotrexate between groups. In an intention-to-treat analysis, an ACR20 response was achieved in $67.9 \%$ of the patients treated with abatacept compared with $39.7 \%$ under placebo $(P<0.001)$. Similarly, ACR50 and ACR70 response rates were significantly higher in abatacept-treated patients (Fig. 3).

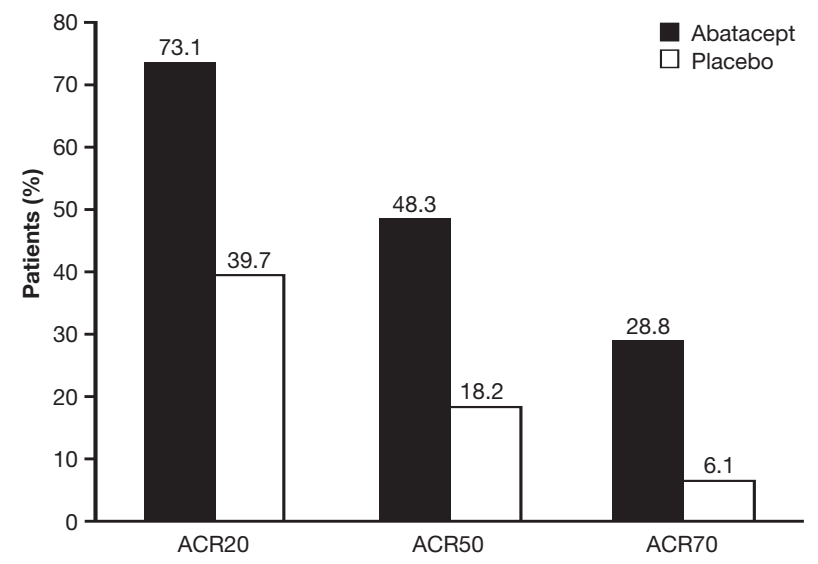

Fig. 3 ACR response after 1 year of abatacept versus placebo in methotrexate-resistant rheumatoid arthritis (AIM trial) (Kremer et al. 2006). The ACR20 $(50,70)$ definition of response specifies a 20\% (50\%, 70\%) improvement over baseline in swollen and tender joints and in $3 / 5$ of the remaining core data set measures

Between 6 and 12 months, all ACR responses continually improved in patients receiving abatacept, but not so under placebo treatment. At 1 year, ACR20 responses had increased to $73.1 \%$ versus $39.7 \%$, ACR50 responses were $48.3 \%$ versus $18.2 \%$, and ACR70 responses were $28.8 \%$ versus $6.1 \%$ after treatment with abatacept versus placebo, respectively $(P<0.001)$. Percentages of patients with ACR50 and ACR70 responses significantly increased from 6 to 12 months $(P<0.001)$. Of the patients with ACR20 after 6 months, $42.9 \%$ of those receiving abatacept achieved ACR50 after 1 year 
compared with $14.3 \%$ of placebo recipients, and $21 \%$ versus $2 \%$ improved to ACR70 (Dougados et al. 2007b).

Physical function significantly improved after 1 year in more patients receiving treatment with abatacept than placebo $(63.7 \%$ vs $39.3 \% ; P<0.001)$. Baseline disease activity was at similar high levels in both groups (DAS-28, 6.4). At 6 and 12 months, 30.1\% and $42.5 \%$ of the abatacept group, respectively, had a DAS-28 of $\leq 3.2$ (i.e. low disease activity), compared with $10.0 \%$ and $9.9 \%$ of the placebo group, respectively $(P<0.001)$. Abatacept induced a DAS-28 score of $<2.6$ (i.e. disease remission) in $14.8 \%$ of patients, whereas this was observed in $2.8 \%$ of the patients receiving placebo at 6 months and in $23.8 \%$ versus $1.9 \%$ at 1 year $(P<0.001)$. Remission was observed after 1 year in $35.6 \%$ of the abatacept group who achieved a DAS-28 score of $\leq 3.2$ after 6 months, in contrast to none of the placebo group (Dougados et al. 2007b).

Combined abatacept and methotrexate treatment leads to significant improvements across a wide range of quality-of-life domains in patients with RA (Russell et al. 2007). In a similar pattern to the ATTAIN trial, 2 years of treatment with abatacept decreased the proportion of patients with fatigue, pain, and sleep problems (Dougados et al. 2007a).

\section{Radiologic data}

The 1-year analysis of the AIM trial also included radiographic outcome. Baseline erosion, joint space narrowing, and total scores were similar between the groups, and after 12 months abatacept-treated patients revealed significantly less progression compared with placebo recipients. The median change from baseline in erosion score was 0 for abatacept versus 0.27 for placebo $(P=0.029)$. The median change in total score was 0.25 with abatacept versus 0.53 with placebo $(P=0.012)$. The mean change from baseline was 0.63 with abatacept versus 1.14 with placebo in erosion score, 0.58 with abatacept versus 1.18 with placebo in joint space narrowing score, and 1.21 with abatacept versus 2.32 with placebo in total score (Kremer et al. 2006).

\section{Safety, tolerability, and combination with other DMARDs}

Inhibiting T-cell activation raises concerns over the host's defense against malignancies or infections. Safety issues have been addressed in all phase II and III clinical trials as secondary endpoints. The overall frequency of malignancies was similar in abatacept- and placebo-treated patients $(1.3 \%$ vs $1.1 \%$, respectively) (Bristol-Myers Squibb 2005). During placebocontrolled study phases there have been four cases of lung cancer $(0.2 \%)$ during abatacept treatment, compared with none under placebo. Including open extension studies, 1955 patients were treated with abatacept until February 2005. In this cohort, eight cases of lung cancer (0.21 per 100 patient-years) and four cases of lymphoma (0.10 per 100 patient-years) have been recorded (Bristol-Myers Squibb 2005). The observed number of lung cancer cases is approximately twice what would be expected based on the US general population incidence rates. The expected number of lung cancer events in the RA cohorts ranged from 3.6 to 9.9. Patients with $\mathrm{RA}$, particularly with active disease, are two to four times more likely to develop lymphoma than the general population. However, an epidemiologic study found that the overall incidence rates of malignancy, lung cancer, and lymphoma among 4134 abatacept-treated patients did not differ significantly from those in six cohorts of over 94000 RA patients exposed to nonbiologic DMARDs (Simon et al. 2007a).

The same authors reported that the incidence rates of serious infection with abatacept were similar to those in RA patients taking nonbiologic DMARDs (Simon et al. 2007b). In the placebocontrolled trials infections were observed in $54 \%$ versus $48 \%$ in abatacept- and placebo-treated groups, and serious infection rates were $3.0 \%$ and $1.9 \%$, respectively (Bristol-Myers Squibb 2005). Level 1 evidence (published as an abstract) from a meta analysis of five RCTs on abatacept involving a total of 1960 patients did not reveal a significant increase in the frequency of serious infection compared with placebo (Salliot et al. 2007).

The Abatacept Study of Safety in Use with Other RA Therapies (ASSURE) was designed to assess as a primary objective the safety of abatacept compared with placebo when added to therapy with one or more conventional or biologic DMARDs (Weinblatt et al. 2006). Patients were treated for 1 year in a double-blind, placebo-controlled trial, and the dosage regimen of abatacept was adjusted to bodyweight according to the protocol of the ATTAIN trial. All patients had to continue their "background" DMARD therapy. Secondary endpoints were clinical outcome measures. After 1 year, 836 patients treated with abatacept and 395 patients treated with placebo finished the study, most of whom were on combination with nonbiologic therapies. Almost $13 \%$ of the patients in the abatacept group and $18 \%$ of the placebo group discontinued treatment before the end of the study. Overall adverse events (90\% and $87 \%$, respectively) and serious adverse events ( $13 \%$ and $12 \%$, respectively) were similar for abatecept and placebo. Death occurred in five $(0.5 \%)$ abatacept- and four (0.8\%) placebo-treated patients.

However, in the smaller group of patients on background biologic therapies there was an increase in serious adverse events $(22.3 \%$ vs $12.5 \%)$ and serious infections (2.9\% vs $1.9 \%)$ observed in patients on abatacept compared with placebo. This suggests that the safety profile for patients receiving background DMARDs appears favorable over 1 year but is less so in those patients on background biologic therapies.

A recent subanalysis of the phase IIlb ARRIVE (Abatacept Researched in Rheumatoid Arthritis Patients with an Inadequate Response to Validate Effectiveness) trial indicates that a wash-out period is not required before initiating abatacept in patients who have failed anti-TNF treatment (Schiff et al. 2007). The frequency of adverse events (including those of a serious nature), infection, neoplasm, drug discontinuation, or death were not significantly different between patients who had stopped anti-TNF medication $\geq 2$ months prior to starting abatacept $(n=370)$ and those who had received anti-TNF therapy within 2 months of starting abatacept $(n=472)$. 
Experimental data from animal models suggest that the combination of biologic DMARDs may be beneficial (Zwerina et al. 2005). In a recent trial 121 patients with active disease despite etanercept therapy were randomized to receive abatacept $2 \mathrm{mg} / \mathrm{kg}$ or placebo while continuing etanercept (Weinblatt et al. 2007). On completion, data revealed only marginal benefit of the combination (ACR20 and ACR50 responses after 6 months $48.2 \%$ and $30.6 \%$, respectively, vs placebo). No further major improvement was achieved by increasing the abatacept dose to $10 \mathrm{mg} / \mathrm{kg}$ during the long-term extension phase. Moreover, the rate of adverse events including serious adverse events ( $16.5 \%$ vs $2.8 \%$, respectively) as well as serious infections (3.5\% vs $0 \%$, respectively) was significantly higher in the combination therapy arm compared with placebo. In summary, therefore, the combined use of abatacept and biologic DMARD therapy is not recommended.

\section{Economic evidence}

Pharmacoeconomic evidence on the use of abatacept in RA is limited. Using results from the AIM trial in a simulated population of female patients aged 55 to 64 years with moderate to severe RA and inadequate response to methotrexate, the cost effectiveness of abatacept was estimated to be $\$$ US47910 per quality-adjusted life-year (QALY) gained over a 10-year period, and \$US43 041 per QALY over a lifetime (Vera-Llonch et al. 2007). Abatacept was calculated to result in 1.2 additional QALYs per patient for a mean cost of \$US103601 compared with \$US52175 for methotrexate alone over 10 years, and two additional QALYs at a cost of \$US147853 versus \$US80096 over a lifetime.

An analysis conducted for the National Institute for Health and Clinical Excellence (NICE) found that the incremental costeffectiveness ratio (ICER) of abatacept compared with methotrexate was $£ 25395$, which is within a QALY threshold of $£ 30000$ (NICE 2007). This estimate assumed disease progression rates of 0.015 increases in HAQ score per year for abatacept and 0.06 for methotrexate. Underlying disease progression was indentified as the main driver of cost effectiveness. Further analysis assuming a disease progression rate of 0.03 for abatacept and 0.045 for methotrexate in HAQ score found an ICER of $£ 33567$ per QALY, and £28445 with corresponding rates of 0.03 and 0.06 . The ICER for abatacept increased to around $£ 70000$ if it was assumed that disease progression was 0.012 with conventional DMARDs and 0.009 with abatacept.

\section{Patient group/population}

Abatacept is indicated for use in adult patients with moderately to severely active RA who have had an inadequate response to DMARDs including TNF antagonists, to inhibit the progression of structural damage, improve physical function, and reduce signs and symptoms of disease. It may be used as monotherapy or in combination with other DMARDs. Concomitant use with TNF antagonists if not recommended, although a wash-out period before beginning abatacept does not appear to be required.
Prescribing information also states that caution should be exercised when administering abatacept to elderly patients and in those with active or a history of recurrent infections. Patients should be screened for tuberculosis before beginning treatment with immunomodulators such as abatacept.

\section{Dosage, administration, and formulations}

Abatacept should be given as a 30 -min intravenous infusion at a dose of $500 \mathrm{mg}$ for patients with bodyweight $<60 \mathrm{~kg}, 750 \mathrm{mg}$ in those weighing 60 to $100 \mathrm{~kg}$, and $1 \mathrm{~g}$ in patients $>100 \mathrm{~kg}$. The drug should be given 2 and 4 weeks after the first dose, then every 4 weeks thereafter.

Abatacept is supplied as lyophilized powder for intravenous infusion in single-use $250 \mathrm{mg}$ vials.

\section{Place in therapy for abatacept in rheumatoid arthritis}

Anti-TNF agents have improved the outcome of RA patients, but there are still some unmet medical needs. Up to $25 \%$ of patients treated with available biologic DMARDs show no satisfactory response. There are essentially three options today if, in addition to conventional DMARDs, therapy with a TNF blocker has failed: (a) switch to another TNF blocker, which is often successful; (b) deplete B cells by rituximab; and (c) block costimulation with abatacept. Results from clinical trials show that abatacept can be given as monotherapy or in combination with other conventional DMARDs. Therefore, in December 2005 the FDA approved abatacept for the treatment of patients with moderately to severely active RA who have had an inadequate response to one or more DMARDs, such as methotrexate or TNF antagonists. Similarly, on May 21, 2007 the European Agency for the Evaluation of Medicinal Products approved abatacept for the treatment of patients with moderately to severely active RA who have had an inadequate response to at least one TNF-blocking therapy or in case of contraindications to anti-TNF therapy. At about the same time, the approved indication for abatacept was updated by the FDA to include the inhibition of structural damage progression.

The studies on abatacept (Table 8) show that ACR20 response rates reach a plateau after 3 months of treatment, and the

Table 8 | Overview of abatacept trials

\begin{tabular}{|llll|}
\hline Reference & $\begin{array}{l}\text { Clinical trial } \\
\text { phase }\end{array}$ & Trial name & $\begin{array}{l}\text { Primary } \\
\text { outcome }\end{array}$ \\
\hline Weinblatt et al. 2007 & Ilb & - & Safety \\
Weinblatt et al. 2006 & III & ASSURE & Safety \\
Kremer et al. 2006 & III & AIM & Efficacy \\
Genovese et al. 2006 & III & ATTAIN & Efficacy \\
Kremer et al. 2005 & Ill & - & Efficacy \\
Kremer et al. 2003 & II & - & Efficacy \\
Moreland et al. 2002 & II & - & Efficacy \\
\hline
\end{tabular}


ACR50 and ACR70 responses seem to level off at 6 to 8 months. Improvement appears to continue out to 1 year or even longer. The radiographic data from the AIM trial demonstrate a slowing of joint erosion by about $50 \%$ after 1 year of abatacept treatment compared with placebo. Trials of 1- and 2-year duration with infliximab, etanercept, and adalimumab have consistently shown less $\mathrm{x}$-ray progression, with joint erosion slowed on average by $80 \%$ to $90 \%$.

Abatacept seemed to exert comparable clinical efficacy compared with infliximab after 6 months (Schiff et al. 2006), with greater efficacy after 1 year as assessed by DAS-28 score and EULAR response criteria (Dougados et al. 2007c). However, no radiographic data were reported in these abstracts, and the dose of infliximab used $(3 \mathrm{mg} / \mathrm{kg}$ every 8 weeks) may have been suboptimal. In those patients with RA refractory to anti-TNF treatment, response rates seem similar under therapy with abatacept or rituximab, which has also been approved for anti-TNF-resistant RA patients (Smolen et al. 2007). While the combination of biologic response modifiers is theoretically appealing and while animal data would argue for this approach, clinical results have so far been disappointing. In fact, no benefit could so far be shown with any combination, while adverse events were increased in most cases. Although no cases of tuberculosis have been observed so far, the fact that abatacept compromises T-cell immunity requires an adequate screening for latent infection before initiating therapy. Therefore, similar to anti-TNF therapy, patients with an increased risk for such infections should be excluded from abatacept treatment or monitored cautiously. A wash-out period in patients failing anti-TNF does not however appear to be necessary before initiating abatacept.

Limited information was identified addressing the pharmacoeconomic aspects of a treatment with abatacept. The cost of abatacept is dependent on dosage; the recommendend dosages for one infusion are $500 \mathrm{mg}$ for patients $<60 \mathrm{~kg}$, $750 \mathrm{mg}$ for patient between 60 to $100 \mathrm{~kg}$, and $1 \mathrm{~g}$ for patients $>100 \mathrm{~kg}$. The annual cost per patient therefore ranges from \$US10105 to \$US20210 depending on the dosage used (\$US15158 for a $75 \mathrm{~kg}$ patient) and is comparable to other biologics (National PBM 2006). The cost effectiveness of abatacept in women unresponsive to methotrexate was calculated to be \$US43041 per QALY, which falls within the threshold judged to be acceptable by many healthcare providers. However, in October 2007 NICE in England and Wales judged abatacept to be not cost effective in patients with RA, despite an ICER of $£ 25395$ per QALY estimated from a model based on the patient population in the ATTAIN trial.

In summary, abatacept is an effective drug for treating patients with RA, and represents an interesting option especially for those with an unsatisfactory response to anti-TNF therapy. It appears to have a comparable cost and safety profile versus other biologics, but as with other biologics, the physician needs to monitor treatment carefully, particularly with respect to malignancy and infection.

\section{Acknowledgments}

Professor Köller has participated in advisory boards for Abbott, Bristol-Myers Squibb, Pfizer, Roche, Schering-Plough, and Wyeth. He has also received grants from Schering-Plough.

\section{References}

Arnett FC, Edworthy SM, Bloch DA, et al. The American Rheumatism Association 1987 revised criteria for the classification of rheumatoid arthritis. Arthritis Rheum. 1988;31:315-324.

Breedveld FC, Weisman MH, Kavanaugh AF, et al. The PREMIER study: a multicenter, randomized, double-blind clinical trial of combination therapy with adalimumab plus methotrexate versus methotrexate alone or adalimumab alone in patients with early, aggressive rheumatoid arthritis who had not had previous methotrexate treatment. Arthritis Rheum. 2006;54:26-37

Bristol-Myers Squibb Company. Briefing document for abatacept (BMS188667). Biological license application 125118. Princeton, NJ: Bristol-Myers Squibb Company; September 2005. Available at: http://www.fda.gov/ohrms/dockets/ac/05/briefing/2005-4170B1_01_01-BMSAbatacept.pdf (accessed June 2007).

Dougados M, Russell A, Li T, et al. Abatacept reduces fatigue and pain severity and sleep problems through 2 years in rheumatoid arthritis patients in the AIM and ATTAIN trials. Ann Rheum Dis. 2007a;66(Suppl. II):429. Abstract SAT0005.

Dougados M, Emery P, Westhovens R, et al. Abatacept provides increasing improvements in clinical measures of disease activity over time: results from the AIM trial. Ann Rheum Dis. 2007b;66(Suppl. II):429. Abstract SAT0004.

Dougados M, Keiserman M, Codding C, et al. Efficacy of abatacept or infliximab treatment in rheumatoid arthritis patients with an inadequate response to methotrexate: results from a 1-year double-blind, randomized, placebo-controlled trial. Ann Rheum Dis. 2007c;66(Suppl. II):88. Abstract OP0118.

Doyle JJ. Economic and quality-of-life impact of rheumatoid arthritis. Manag Care. 2001;10:15-18.

Dumont FJ. Technology evaluation: abatacept, Bristol-Myers Squibb. Curr Opin Mol Ther. 2004;6:318-330.

Edwards JC, Szczepanski L, Szechinski J, et al. Efficacy of B-cell-targeted therapy with rituximab in patients with rheumatoid arthritis. $\mathrm{N} \mathrm{Engl} \mathrm{J} \mathrm{Med.}$ 2004;350:2572-2581.

Emery P, Kosinski M, Li T, et al. Treatment of rheumatoid arthritis patients with abatacept and methotrexate significantly improved health-related quality of life. J Rheumatol. 2006;33:681-689.

FDA (Food and Drug Administration). CDER new molecular entity (NME) drug and new biologic approvals in calendar year 2005. December 31, 2005. Available at: http://www.fda.gov/cder/rdmt/InternetNME05.htm (accessed June 2007).

Felson DT, Anderson JJ, Boers M, et al; American College of Rheumatology. Preliminary definition of improvement in rheumatoid arthritis. Arthritis Rheum. 1995;38:727-735.

Gabriel SE. The epidemiology of rheumatoid arthritis. Rheum Dis Clin North Am. 2001;27:269-281.

Genovese MC, Bathon JM, Martin RW, et al. Etanercept versus methotrexate in patients with early rheumatoid arthritis: two-year radiographic and clinical outcomes. Arthritis Rheum. 2002;46:1443-1450.

Genovese MC, Becker JC, Schiff M, et al. Abatacept for rheumatoid arthritis refractory to tumor necrosis factor alpha inhibition. $N$ Engl J Med. 2005;353:1114-1123.

Goronzy JJ, Weyand CM. T-cell regulation in rheumatoid arthritis. Curr Opin Rheumatol. 2004;16:212-217.

Hassett AL, Maclean JR, Stuart MR, et al. An observational evaluation of psychological well-being in rheumatoid arthritis in the ATTAIN trial for abatacept. Ann Rheum Dis. 2007;66(Suppl. II):440. Abstract SAT0037-AHP. 
Keystone EC, Kavanaugh A. What to do with TNF failures. Expert Opin Drug Saf. 2005;4:149-155.

Knoerzer DB, Karr RW, Schwartz BD, Mengle-Gaw LJ. Collagen-induced arthritis in the BB rat. Prevention of disease by treatment with CTLA-4-Ig. $J$ Clin Invest. 1995;96:987-993.

Köller MD. Targeted therapy in rheumatoid arthritis. Wien Med Wochenschr. 2006;156:53-60.

Kremer JM, Westhovens R, Leon M, et al. Treatment of rheumatoid arthritis by selective inhibition of T-cell activation with fusion protein CTLA4Ig. N Engl J Med. 2003;349:1907-1915.

Kremer JM. Cytotoxic T-lymphocyte antigen 4-immunoglobulin in rheumatoid arthritis. Rheum Dis Clin North Am. 2004;30:381-391, viii.

Kremer JM, Dougados M, Emery P, et al. Treatment of rheumatoid arthritis with the selective costimulation modulator abatacept: twelve-month results of a phase Ilb, double-blind, randomized, placebo-controlled trial. Arthritis Rheum. 2005;52:2263-2271.

Kremer JM, Genant HK, Moreland LW, et al. Effects of abatacept in patients with methotrexate-resistant active rheumatoid arthritis: a randomized trial. Ann Intern Med. 2006;144:865-876.

Lassere M. Pooled metaanalysis of radiographic progression: comparison of Sharp and Larsen methods. J Rheumatol. 2000;27:269-275.

Mikuls TR, Saag KG. Comorbidity in rheumatoid arthritis. Rheum Dis Clin North Am. 2001;27:283-303.

Moreland LW, Alten R, Van den Bosch F, et al. Costimulatory blockade in patients with rheumatoid arthritis: a pilot, dose-finding, double-blind, placebo-controlled clinical trial evaluating CTLA-4Ig and LEA29Y eighty-five days after the first infusion. Arthritis Rheum. 2002;46:1470-1479.

National PBM (Pharmacy Benefits Management Strategic Healthcare Group). Abatacept $\left(\right.$ Orencia $^{\circledR}$ ) drug monograph. March 2006. Available at: http://www.pbm.va.gov/monograph/Abatacept,\%20Monograph.pdf (accessed June 2007).

NICE (National Institute for Health and Clinical Excellence). Final appraisal determination: abatacept in rheumatoid arthritis. London: NICE; 2007. Available at: http://guidance.nice.org.uk/download.aspx?o=461128 (accessed November 2, 2007).

Pincus T, Larsen A, Brooks RH, Kaye J, Nance EP, Callahan LF. Comparison of 3 quantitative measures of hand radiographs in patients with rheumatoid arthritis: Steinbrocker stage, Kaye modified Sharp score, and Larsen score. J Rheumatol. 1997;24:2106-2112.

Prevoo M L, van't Hof MA, Kuper HH, van Leeuwen MA, van de Putte LB, van Riel PL. Modified disease activity scores that include twenty-eight-joint counts. Development and validation in a prospective longitudinal study of patients with rheumatoid arthritis. Arthritis Rheum. 1995;38:44-48.

Quattrocchi E, Dallman MJ, Feldmann M. Adenovirus-mediated gene transfer of CTLA-4Ig fusion protein in the suppression of experimental autoimmune arthritis. Arthritis Rheum. 2000;43:1688-1697.

Quinn MA, Conaghan PG, Emery P. The therapeutic approach of early intervention for rheumatoid arthritis: what is the evidence? Rheumatology (Oxford). 2001;40:1211-1220.

Quinn MA, Emery P. Are early arthritis clinics necessary? Best Pract Res Clin Rheumatol. 2005;19:1-17.

Redlich K, Hayer S, Ricci R, et al. Osteoclasts are essential for TNF-alphamediated joint destruction. J Clin Invest. 2002;110:1419-1427.

Russell AS, Wallenstein GV, Li T, et al. Abatacept improves both the physical and mental health of patients with rheumatoid arthritis who have inadequate response to methotrexate treatment. Ann Rheum Dis. 2007;66:189-194.

Salliot C, Gossec L, Dougados M. Rituximab, abatacept and anakinra do not increase the risk of serious infections: a metaanalysis of published randomised controlled trials. Ann Rheum Dis. 2007;66(Suppl. II):436. Abstract SAT0027.

Schiff M, Keiserman M, Codding C, et al. The efficacy and safety of abatacept or infliximab in RA patients with an inadequate response to MTX: results from a 1-year double-blind, randomized, placebo-controlled trial. Arthritis Rheum. 2006;54(Suppl.):4117. Abstract.
Schiff M, Pritchard C, Teng J, Bahrt K, Genovese M. The safety of abatacept in patients with active rheumatoid arthritis and an inadequate response to anti-TNF therapy: results from the ARRIVE trial. Ann Rheum Dis. 2007;66(Suppl. II):89. Abstract OP0121.

Scott DL. Pursuit of optimal outcomes in rheumatoid arthritis. Pharmacoeconomics. 2004;22(Suppl.):13-26.

Sfikakis PP, Via CS. Expression of CD28, CTLA4, CD80, and CD86 molecules in patients with autoimmune rheumatic diseases: implications for immunotherapy. Clin Immunol Immunopathol. 1997;83:195-198.

Simon TA, Smitten A, Meng M, et al. Malignancies in the rheumatoid arthritis (RA) abatacept clinical development program: an updated epidemiological assessment. Ann Rheum Dis. 2007a;66(Suppl. II):90. Abstract OP0124.

Simon TA, Smitten A, Meng M, et al. Serious infections in the rheumatoid arthritis abatacept clinical development program: an updated epidemiological assessment. Ann Rheum Dis. 2007b;66(Suppl. II):438. Abstract SAT0032.

Skapenko A, Leipe J, Lipsky PE, Schulze-Koops H. The role of the T cell in autoimmune inflammation. Arthritis Res Ther. 2005;7(Suppl. 2):S4-S14.

Smolen JS, Hayer S, Schett G, et al. Autoimmunity and rheumatoid arthritis. Autoimmun Rev. 2004;3(Suppl. 1):S23.

Smolen JS, Aletaha D, Machold KP. Therapeutic strategies in early rheumatoid arthritis. Best Pract Res Clin Rheumatol. 2005a;19:163-177.

Smolen JS, Redlich K, Zwerina J, Aletaha D, Steiner G, Schett G. Proinflammatory cytokines in rheumatoid arthritis: pathogenetic and therapeutic aspects. Clin Rev Allergy Immunol. 2005b;28:239-248.

Smolen JS, Aletaha D, Koeller M, Weisman MH, Emery P. New therapies for treatment of rheumatoid arthritis. Lancet. 2007 Jun 12; (Epub ahead of print).

Vera-Llonch M, Massarotti E, Shadick N, et al. Cost-effectiveness of abatacept in patients with moderately to severely active rheumatoid arthritis and inadequate response to methotrexate. Ann Rheum Dis. 2007;66(Suppl. II):277. Abstract THU0488.

Webb LM, Walmsley MJ, Feldmann M. Prevention and amelioration of collagen-induced arthritis by blockade of the CD28 co-stimulatory pathway: requirement for both B7-1 and B7-2. Eur J Immunol. 1996;26:2320-2328.

Weinblatt M, Combe B, Covucci A, Aranda R, Becker JC, Keystone E. Safety of the selective costimulation modulator abatacept in rheumatoid arthritis patients receiving background biologic and nonbiologic disease-modifying antirheumatic drugs: a one-year randomized, placebo-controlled study. Arthritis Rheum. 2006;54:2807-2816.

Weinblatt M, Schiff M, Goldman A, et al. Selective costimulation modulation using abatacept in patients with active rheumatoid arthritis while receiving etanercept: a randomised clinical trial. Ann Rheum Dis. 2007;66:228-234.

Weisman $\mathrm{MH}$, Durez $\mathrm{P}$, Hallegua $\mathrm{D}$, et al. Reduction of inflammatory biomarker response by abatacept in treatment of rheumatoid arthritis. J Rheumatol. 2006;33:2162-2166.

Wells G, Li T, Westhovens R, Tugwell P. Increased activity participation and its determinants in rheumatoid arthritis patients treated with abatacept. Ann Rheum Dis. 2007;66(Suppl. II):433. Abstract SAT0017.

Westhovens R, Cole JC, Li T, et al. Improved health-related quality of life for rheumatoid arthritis patients treated with abatacept who have inadequate response to anti-TNF therapy in a double-blind, placebo-controlled, multicentre randomized clinical trial. Rheumatology (Oxford). 2006;45:1238-1246.

Zwerina J, Redlich K, Schett G, Smolen JS. Pathogenesis of rheumatoid arthritis: targeting cytokines. Ann N Y Acad Sci. 2005;1051:716-729.

Correspondence: Marcus D. Köller, Medical University of Vienna, Department of Rheumatology/Internal Medicine III, General Hospital, Währinger Gürtel 18-20, A-1090 Vienna, Austria or at marcus.koeller@meduniwien.ac.at 